\title{
FluoRAS Sensor - Online organic matter for optimising recirculating aquaculture systems
}

\author{
Adam Hambly $\ddagger$, Colin Stedmon $\ddagger$ \\ ‡ Technical University of Denmark, Kgs. Lyngby, Denmark
}

Corresponding author: Adam Hambly (adaha@aqua.dtu.dk)

Reviewable v1

Received: 29 Jan 2018 | Published: 31 Jan 2018

Citation: Hambly A, Stedmon C (2018) FluoRAS Sensor - Online organic matter for optimising recirculating aquaculture systems. Research Ideas and Outcomes 4: e23957. https://doi.org/10.3897/rio.4.e23957

\begin{abstract}
FluorRAS will develop a sensor that can save recycled fish farms $30 \%$ per year in water and energy consumption for water treatment, as well as optimize nitrogen removal. The sensor will be developed in a partnership between engineers (Krüger A / S) and researchers (DTU), and the product will be made available to the entire sector through Danish Aquaculture. Global aquaculture production is expected to double within the next 15 years. Recycling technology has a great potential for supporting environmentally and economically sustainable production. However, the technology has some challenges in balancing both the maintenance of necessary water quality and water treatment costs. Loss of production due to poor water quality is expensive and can be avoided with correct sensor systems. Accumulation of dissolved organic matter and nutrients in the water reduce the effectiveness of UV treatment, is a source of nutrition for opportunistic pathogens, and reduces the effectiveness of the biofilter's removing ammonia. Modern recycling systems are therefore dependent on a network of online sensors that monitor and respond to changes in water quality, but currently there is a need for a sensor to monitor the accumulation of organic matter. FluoRAS aims to fill this gap in technology by developing an online fluorescence sensor. The sensor is based on non-destructive, online optical technology that does not require chemicals and can run continuously.
\end{abstract}




\section{Keywords}

Recirculating Aquaculture System, sensors, nitrogen, ammonia

\section{List of participants}

Patrizio Mariani, Technical University of Denmark

Michael Bech, Kruger A/S

Kaare Michelsen, Danish Aquaculture

\section{Project description}

The purpose of the FluoRAS project is to develop an online sensor that could become an important tool for the optimisation of recirculating aquaculture system (RAS) technology. Controlling organic matter concentrations within aquaculture water will benefit the Danish RAS industry by: enhancing nitrification; reducing water demand; reducing UV treatment energy costs; and controlling nitrogen discharge, resulting in a competitive advantage. Partnering with a state-of-the-art Danish RAS manufacturer (Kruger A/S) and Dansk Akvakultur (The Danish Aquaculture Organisation), the sensor system will be made available for integration into any existing or future commercial Danish RAS production lines, and also as a stand-alone sensor product for custom application by Danish aquaculture operators. With the potential for significant positive environmental effects, and by lowering the cost of RAS production, the project thus covers the entire market value chain, from RAS facilities producers to consumers.

The FluoRAS sensor is based on non-invasive, non-destructive, optical technology that does not require any chemicals, and can be carried out continuously online. The sensor uses underwater fluorescence spectroscopy and will be applied to aquaculture production, providing a real-time monitoring tool to improve the environmental and economic efficiency of RAS. The project is based on a strong proof-of-concept (Hambly et al. 2015) and is a logical progression to overcome environmental and economic hurdles within a growing Danish RAS industry.

Global aquaculture production is expected to double in the next 15 years and RAS are recognised as an important component of sustainable and environmentally green seafood production (OECD 2016). In RAS, the fish are grown in land-based tanks in which the water is continuously pumped through water treatment systems and back into the tanks for reuse. These systems typically reuse between 90 and $99 \%$ of their water volume per day, however, the same property that makes RAS an environmentally friendly production technology, can also cause problems. Recycling of water and low waste discharge causes an accumulation of organic matter and nitrogen which encourages fast microorganism growth. These microorganisms can be toxic and cause up to a complete loss of fish (Moestrup et al. 2014), generating large economic losses. In the event of fast declines in 
water quality and a system "crash" (fish death), a commercial scale RAS can lose up to 400 tonnes of fish product (up to 20 million $\mathrm{Kr}$ ) and 10 months of production time (Krüger A/S data - representative of typical RAS operations). As such, RAS inherently employ a delicate balance between economic sustainability (water consumption and treatment costs) and environmental sustainability (water usage and waste water discharge) to mitigate the risk of a system crash. The most recent Danish system crash was June 30th, 2017, where Langsand Laks lost 250 tonnes of RAS salmon (25\% of their annual production) over a period of 15-20 hours (Anonymous 2017). These unpredictable, yet repeated, failings in commercial RAS indicate that the main issues in the RAS industry are not the product market, nor the cost base, but rather technical issues and the associated risks with not being able to detect water quality problems within a reactive timeframe.

One of the more common water quality problems in RAS is organic matter (OM). From a microbial water quality perspective, OM absorbs UV radiation and shields microbes from UV treatment, resulting in decreased microbial disinfection. For instance, approximately halving the organic matter concentration from 5,8 to $2,3 \mathrm{mg} / \mathrm{L}$ sees a $30 \%$ increase in microbial destruction by UV treatment (He et al. 2012). Organic matter also acts as a food source and substrate for heterotrophic bacterial populations (including opportunistic pathogens). From a chemical water quality perspective, excessive OM decreases a biofilter's ability to remove harmful ammonia from the system via nitrification, and increases the requirements for water treatment before discharging used RAS water into the environment. Commercial RAS rely on a network of online sensors to monitor and react to potentially rapid changes in water quality, such as $\mathrm{pH}$, temperature, oxygen and $\mathrm{CO}_{2}$ levels. However, an online sensor for OM does not yet exist for the RAS industry. Water treatment and subsequent management for OM is therefore essentially carried out "blind". FluoRAS aims to fill this important technology gap by developing an online organic matter sensor, allowing RAS operators to minimise the organics and nutrient loading, as well as water usage, and maximise the efficiency of water treatment processes.

As it is an important component of water quality, OM has been a topic of increasing interest within both natural and engineered aquatic systems. A proportion of the OM within these systems consists of fluorescent dissolved organic matter (fDOM) and its properties can be characterised using fluorescence spectroscopy. FDOM analysis has been successfully used to trace ocean outfalls, confirm ship ballast exchange in sensitive marine environments, detect low levels of river contamination, and to assess drinking water, recycled water and wastewater treatment performance and water quality monitoring (Hudson et al. 2007). Within the fDOM analysis field, fluorescence excitation-emission matrix (EEM) spectroscopy has emerged as the state-of-the-art technique and is increasingly used as a common analytical tool for water sciences. A matrix of fluorescence data is produced when a sample's fluorescence emission spectrum is recorded across consecutive excitation wavelengths, forming a three-dimensional fluorescent matrix, or "fingerprint" of water character and composition (Fig. 1). These fluorescence EEMs provide a detailed map of the organic matter within the complex water mixture. Multivariate data analysis techniques such as parallel factor analysis (PARAFAC) can then decompose EEM datasets into their independently varying organic matter components, thus reducing the 
data-rich EEM analyses to the most relevant wavelengths, from which a simplified, fast, low powered, online monitoring sensor can be constructed.

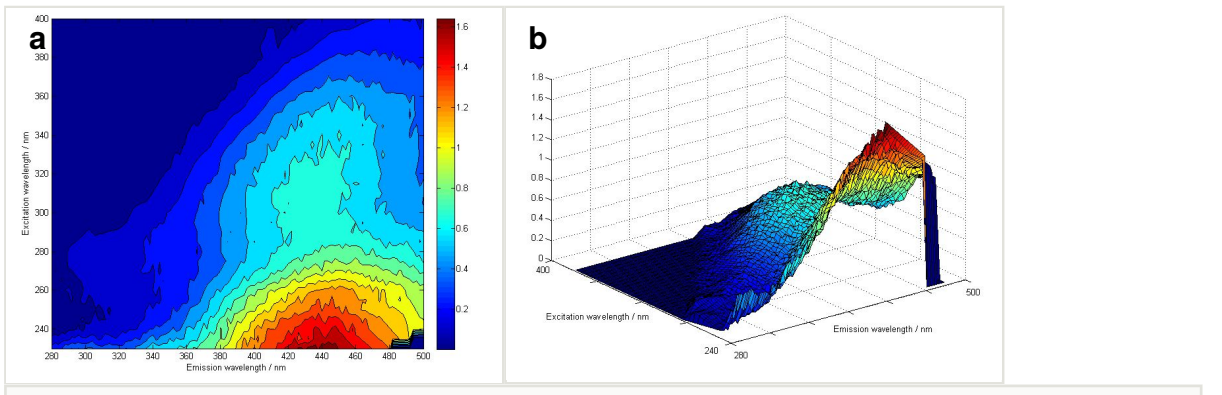

Figure 1.

An example of a fluorescence EEM "fingerprint" of drinking water. Multivariate modelling of EEM datasets allows the most important areas of the EEM to be identified, and used for simplified online fluorescence sensors.

a: EMM viewed as a contour plot doi

b: EMM viewed as a waterfall plot doi

The number of commercially available, simplified fluorescence sensors for aquatic applications has been slowly increasing; and each has a targeted range of wavelengths and sensitivities that are designed and tested for specific applications. So far, these sensors have been developed for oceanographic applications and as yet, no such sensor has been developed and optimised for use specifically within RAS. There is clear potential for the RAS industry to benefit from development of such a sensor, and this is precisely what the FluoRAS project aims to do: develop a database of fluorescence EEMs, which can then be used to design a simplified fluorescence sensor for online organic matter monitoring of any existing RAS.

The project combines expertise in online organic matter analysis and multivariate data modelling (DTU Aqua), with project partners that provide access to state-of-the-art, commercial-scale RAS (Krüger A/S), and regular contact with the wider Danish RAS industry (DanskAkvakultur) for on-going design feedback and dissemination. This combination is key to the successful development of an online, RAS organic matter sensor, to lower Danish RAS production costs, decrease operational water quality risks, and encourage sector growth by increasing the green and economic sustainability of entire Danish RAS industry.

To achieve this, the FluoRAS project will be divided into 5 Work Packages, which will be carried out over 3,25 years:

WP1. Benchmark EEM Dataset - RAS Variability (TRL1): The bulk of this work package will be regular, discrete water sampling of operating commercial RAS(s) to capture the full range of RAS water quality variability that is to be expected within a full production cycle. This will include short-term, high frequency sampling to capture diurnal variability due to daily fish behaviour patterns, feeding patterns and environmental cycling conditions, as well 
as long-term, lower frequency sampling to capture changes in water quality due to season and fish growth cycles (typically up to 12 months) amongst others. Nutrient and bulk water quality analyses will accompany fluorescence EEM spectroscopy analyses. WP1 sampling will be carried out at Kruger's RAS facilities in Denmark, which are representative of typical RAS facilities in operation throughout Denmark. They will therefore serve as an excellent model system for design of the FluoRAS sensor system. Samples will be taken from throughout the system, and analysis of RAS water samples will be conducted at DTU.

Output to WP3: Full RAS cycle EEM reference dataset, for multi-way and multivariate analysis.

WP2. Benchmark EEM Dataset - RAS Failure (TRL1): This work package will consist of laboratory studies concerning potential contamination of RAS water due to hazardous events. These events include feeding failure (severe over and underfeeding), individual water treatment process failures (filtration and UV failure), and operational changes, which will be confirmed by Dansk Akvakultur with input received from consultation with the Danish RAS industry. These studies will be conducted at DTU on multiple large volume water samples provided by project partners, and will analytically document the changes in $\mathrm{OM}$, nutrients, and bulk water quality according to the type, and severity of the contamination or failure events.

Output to WP3: RAS failure EEM reference dataset, for multi-way and multivariate analysis.

WP3. Optimise Sensor Specifications (TRL2): WP1 and WP2 will require data analysis and modelling to determine the optimal wavelengths for monitoring of RAS water for organic matter. This will be carried out at DTU Aqua by way of extensive multi-way analysis and multivariate modelling (PCA, PLS and PARAFAC analysis). PARAFAC analysis will deconstruct the EEM datasets into individually varying organic matter components, which can then be combined with nutrient and bulk water quality datasets to determine the potential for relevant proxy measurements by optical methods.

Outputs to WP4:

1. optimal wavelengths for monitoring RAS organic matter water quality; and

2. statistical correlations with other nutrients/bulk water quality parameters to assess the use of specific optical wavelengths as proxies for additional water quality information and hazardous event detection.

WP4. Online System Proof of Concept (TRL3-4): This work package leads directly on from the outcomes of WP3, for the design, construction and operational performance assessment of the FluoRAS sensor system. A commercially available fluorescence emission sensor (Ocean Optics) will be utilised along with custom-built excitation light sources, with wavelengths as specified by the outcomes of WP3. Software will also be developed to process the fluorescence signals for maximum sensitivity. Krüger A/S will be responsible for sensor construction, with design and laboratory performance testing by DTU Aqua. Krüger A/S will also develop the software required for its integration into existing monitoring systems, with signal processing advice from DTU Aqua. 
Output to WP5: functional prototype FluoRAS sensor and software for full-scale system trials.

WP5. Full-Scale Trials and Industry Dissemination (TRL5): The final work package involves the long-term, field-testing of the FluoRAS sensor system developed in WP4. This will be carried out on a commercial-scale RAS (Hanstholm, Denmark, operated by Krüger A/S) over a full RAS operational cycle of 12 months. The online, continuous monitoring system will be quality controlled and verified with parallel discrete sampling and laboratory analysis in a similar manner to WP1.

Output:

1. A calibrated and verified online fluorescence monitoring system - the FluoRAS sensor system - ready for transfer to the Danish RAS industry.

2. Dissemination workshops with the Danish RAS industry on the function and use of the FluoRAS sensor.

\section{Impact on green sustainability}

The green sustainability effects of the FluoRAS project are based on the development of an online organic matter sensor, allowing the implementation and optimisation of organic matter removal. This leads to significant positive green effects within three main areas: (a) nitrogen reduction; (b) decreased climate impacts $\left(\mathrm{CO}_{2}\right)$; and (c) more sustainable use of resources.

1. Nitrification efficiency and sustainable use of resources: A typical commercial RAS will require the discharge of $5-10 \%$ (or more) of its total water volume per day water which contains high concentrations of nitrogen. Nitrification (the transformation and removal of ammonia from fish excretion) through biofilters is the main treatment pathway for nitrogen removal in RAS. Organic matter has been welldocumented to interfere with the this process, causing up to a $30 \%$ reduction in nitrification efficiency (Eding et al. 2006). The biofilter process is an extremely important bottleneck for the removal of nitrogen from RAS water, and by maximising its efficiency through organic matter removal, this ensures minimal $\mathrm{N}$-discharge and a lower environmental footprint for RAS. This is a particularly relevant for the Danish governments strategy to reduce nitrogen load in aquaculture by $20 \%$ to 2020 (Ministry of Environment 2014). As ammonia is toxic to the aquatic organisms contained within the RAS, nitrification efficiency of the biofilters also limits the amount of water reuse the system can handle. By increasing the biofilter nitrification efficiency by up to $30 \%$ through online organic matter detection and optimisation, more water can be reused and the systems water consumption can therefore be reduced. For current Danish RAS production, this translates to approximately 65,6 tonnes of $\mathrm{N}$ reduction, and a $175.200 \mathrm{~m} 3$ reduction in water usage, per year.

2. UV treatment efficiency: UV treatment is a necessary but energy intensive process for microbial disinfection within RAS, and the presence of organic matter makes this 
even more energy intensive. Organic matter can absorb UV radiation or shield microbes from UV radiation, hence resulting in lower delivered UV doses and reduced microbial disinfection. For instance, by halving the organic matter concentration from 5,8 to $2,3 \mathrm{mg} / \mathrm{L}$, there is an improvement in microbial destruction by over $30 \%$ (He et al. 2012), which conservatively translates to a reduction of 15,6 tonnes of $\mathrm{CO}_{2}$ per year in energy use for current Danish RAS production. It should also be noted, that due to the lack of online organic matter monitoring in current RAS, UV treatments are therefore aimed at substantial overdosing of UV, in order to mitigate the risk of a potential microbial outbreak. The further savings from optimising this process to actual UV requirements (which will already be $30 \%$ lower) are operator dependent (i.e. it depends on how much each individual operator is overdosing their system), and hence cannot be calculated accurately - but are assumed to be significant.

The green effects (Table 1) are calculated from statistics and operational figures provided by the project partners recirculating aquaculture systems (annual usage data, Krüger A/S), and are calculated from a single RAS unit (which equates to $25 \%$ of current Danish production). These RAS units are considered state-of-the-art in operation and efficiency, and so the calculated savings are very conservative for extrapolation to other Danish RAS units. At this point we must further emphasise the predicted RAS industry growth rates, which are expected to more than double the industry size by 2030 . As such, this would also double the calculations for both green effects and economic effects within sections (Table 1 and Table 2).

Table 1.

Impact table - Green Sustainability

\begin{tabular}{|l|l|l|l|l|}
\hline Parameters & Effect & Distribution & Total Effecct & Reference \\
\hline $\begin{array}{l}\text { Minimizing the nutrient surplus } \\
\text { (Nitrogen) }\end{array}$ & $\begin{array}{l}\text { Up to } 30 \% \\
\text { saved }\end{array}$ & $219,2 \mathrm{t} /$ year & $65,6 \mathrm{t} /$ year & $\begin{array}{l}\text { Eding et al. } \\
2006\end{array}$ \\
\hline $\begin{array}{l}\text { Limiting climate effects } \\
\left(\mathbf{C O}_{\mathbf{2}} \text { equivalents) }\right.\end{array}$ & $\begin{array}{l}\text { Up to } 30 \% \\
\text { saved }\end{array}$ & $52 \mathrm{t} /$ year & $16 \mathrm{t} /$ year & He et al. 2012 \\
\hline Sustainable water utilization & Up to 30\% & $\begin{array}{l}584.000 \mathrm{~m}^{3} / \\
\text { year }\end{array}$ & $\begin{array}{l}175.200 \mathrm{~m}^{3} / \\
\text { year }\end{array}$ & $\begin{array}{l}\text { Eding et al. } \\
2006\end{array}$ \\
\hline
\end{tabular}

Table 2.

Impact table - Economic sustainability

\begin{tabular}{|l|l|l|l|l|}
\hline Parameters & Effect & Distribution & Total Effecct & Reference \\
\hline further economic impact & Water use & 26 million & 7.9 million & Eding et al. 2006 \\
& UV & DKK & DKK & He et al. 2012 \\
& electricity & 174.000 DKK & 52.120 DKK & \\
\hline $\begin{array}{l}\text { quality and added value per raw } \\
\text { material unit }\end{array}$ & 100.000 & $30-300$ units & $3-30$ million & DNB Markets \\
& DKK & & DKK & 2017 \\
& Per sensor & & & \\
\hline
\end{tabular}




\section{Impact on economical sustainability}

The economic effects and green effects of online sensing and optimising of organic matter loads in RAS are inherently linked. Decreasing organic matter loads leads to decreased water consumption and more efficient nitrogen removal, which thereby lowers the UV treatment requirements and provides positive environmental effects. Decreased annual UV treatment requirements and annual water consumption further leads to direct economic savings for RAS operators.

The economic effects within FluoRAS are projected to come from three main areas:

1. Reduced electricity consumption: as outlined in Table 2, a reduction in organic matter within the systems will lead to up to $30 \%$ less UV treatment required. As UV generation is an energy-intense process, there are significant cost savings from the subsequent reduction in electricity requirements, which translates to a reduction in electricity costs by up to 52.120 DKK per year within Denmark;

2. Reduced water consumption: RAS water recirculation relies on the ability to remove toxic ammonia from the tank water quickly, via nitrification in the biofilters. Nitrification therefore often limits the amount of water reuse the system can handle. By increasing nitrification efficiency by up to $30 \%$ (Eding et al. 2006), this also provides the opportunity to reduce the systems water consumption by up to $30 \%$. This translates to a saving of up to 7.884.000 DKK per year in water costs, for the current size of the Danish RAS industry. This calculation is based on the conservative water consumption figures of a Kruger RAS unit (100 L/kg feed/day), which is a low water reuse requirement in comparison to the rest of the RAS industry. It should be noted that with the projected global increase in aquaculture to 2030 (World Bank 2013), also comes an equivalent increase in the calculated annual savings.

3. FluoRAS sensor revenue: Global RAS expansion by 2020 is expected to be over 150.000 tonnes (DNB Markets 2017) - approximately 500 million DKK production value by current pricing. At typical RAS production sizes (500-5.000 t), this would equate to anywhere between 30-300 new RAS facilities could come online, which could all benefit from the FluoRAS sensor within this timeframe.

\section{Organisation and Leadership}

The FluoRAS project requires highly specific knowledge, skills, and facilities, which can be brought together by collaboration between DTU Aqua, Kruger A/S, and DanskAkvakultur. The project is to be hosted at DTU-Aqua - National Institute of Aquatic Resources - an institute at the Technical University of Denmark (DTU), which conducts teaching and research into all types of aquatic habitats. The institute is located at DTU's main campus (Lyngby) and equipped with new analytical facilities for carrying out a broad spectrum of RAS water quality analyses, including the current state-of-the-art in fluorescence EEM analysis (Horiba Aqualog), UV absorbance spectroscopy, nutrient analyses, high 
performance liquid chromatography (HPLC), and total and dissolved organic carbon (TOC and DOC) analyses. The project will be co-ordinated by Dr Colin Stedmon and DTU Aqua, who will also be responsible for project management, with Dr Adam Hambly carrying out the majority of experimental work with technical advice from Dr Patrizio Mariani. Dr Colin Stedmon is one of Europe's leading researchers in the field of fluorescence characterisation of organic matter in aquatic systems, and is responsible for developing the now widely applied and cited methods to characterise organic matter fluorescence. Dr Adam Hambly, is one of only a handful of researchers in the world to have worked with and published peer-reviewed literature on in situ fluorescence techniques, and one of even fewer to have experience with in situ and online fluorescence to monitor various anthropogenic water sources, including aquaculture. Together they have published the first paper investigating the potential of fluorescence spectroscopy for characterising $\mathrm{OM}$ in RAS water (Hambly et al. 2015). Dr Patrizio Mariani currently leads DTU Aqua's research area of observational technologies, aiming to create new optical technologies for marine, freshwater and oceanographic applications. Combined, this provides expertise in fluorescence EEM analysis, multivariate data analysis and modelling, water chemistry, marine biology and sensor design.

Dr Michael Bech is the RAS project developer for Krüger A/S, a Danish company who develops state of the art RAS systems that integrate advanced water treatment technologies, together with Erik Gutzman (aquaculture specialist), Kim Sundmark (Senior process engineer) and Anders Bertelsen (Aquaculture project manager). Krüger A/S will provide access to state-of-the-art commercial RAS facilities in Denmark, along with their expert knowledge in commercial RAS design, operation and management. Kaare Michelsen (chief technology and advisory consultant at Dansk Akvakultur), will provide direct access to the rest of the Danish RAS industry, for important design feedback and technology dissemination. This combination and crossover of analytical, practical, and industry knowledge between the project partners provides the knowledge and synergy for the FluoRAS project to see successful completion of all work packages.

WP1 and WP2 can both be carried out at DTU Aqua on samples taken from commercial RAS facilities operated by Krüger A/S. Dansk Akvakultur will facilitate feedback from the RAS industry as to detailing the focus of RAS treatment failure types around which to develop WP2 datasets. The multivariate analysis and modelling contained within WP3 is to be carried out by DTU Aqua. WP4 will be jointly shared by DTU Aqua and Krüger A/S, who will perform the necessary design and modifications to a commercially available fluorescence sensor as specified by DTU Aqua, as well as software design for optimal fluorescence signal processing. Tasks within WP5 will be carried out by DTU Aqua, Krüger $\mathrm{A} / \mathrm{S}$, and Dansk Akvakultur, to combine the practicalities of running the new FluoRAS sensor continually within a commercial scale RAS, together with discrete sampling and laboratory analysis for validation, and finally communication and promotion within the Danish RAS industry. All partners will be equally responsible for dissemination activities, though Dr Stedmon will ultimately be responsible for the co-ordination of this process. The project steering committee will consist of three members: Dr Colin Stedmon (DTU Aqua); Dr Adam Hambly (DTU Aqua); and Dr Michael Bech (Krüger A/S). They will be responsible 
for the overall direction of the project, with regular meetings to monitor progress and ensure targets are met. The work plan will be co-ordinated at an initial kick-off meeting with project partners, and progress will be continually re-assessed at regular meetings.

\section{The project's connection with other previous and ongoing projects}

The FluoRAS project will build on the outcomes of pilot trials and results achieved within projects collaborated between DTU Aqua and Krüger A/S, and a number of other international projects. Dr Colin Stedmon and Krüger A/S successfully developed a prototype sensor for drinking water through the combination of two projects:

a) Aquafingerprint (2009-2010, By- og Landskabsstyrelsen, Miljøministeriet); and

b) Aqua Fingerprint Early warning for Contamination of Drinking Water (2011-2012, Naturstyrelsen, Miljøministeriet).

Dr Patrizio Mariani is currently leading the observational technologies research group at DTU Aqua, developing remote operated vehicles for aquatic monitoring. There is great potential for significant knowledge transfer between this and the FluoRAS project. Dr Colin Stedmon and Dr Adam Hambly are both experts in the optical properties of aquatic organic matter, and have utilised these analytical expertise for project applications ranging from oceanography and climate change research to desalination research, drinking water and wastewater treatment optimisation, and drinking water contamination detection. They have also recently published the first paper to utilise fluorescence EEM analysis for the characterisation of RAS (Hambly et al. 2015). This is a very strong proof-of-concept and the FluoRAS sensor project is a logical progression from these earlier studies to overcome environmental and economic hurdles within an expanding Danish RAS industry.

\section{The expected cooperation with relevant companies / institutions / projects both nationally and internationally}

The FluoRAS project will incorporate two project partners for development (Kruger A/S), and dissemination to relevant Danish RAS operators (Dansk Akvakultur). Krüger A/S has its headquarters in Copenhagen, works in close co-operation with Krüger Kaldnes in Norway, and constitutes the core of the aquaculture sector of Veolia. Veolia is a leading global company for waste water treatment systems and drinking water with approximately 200.000 employees in 61 countries, and an interest and expertise in water quality monitoring technology.

The Danish Aquaculture Organisation (DanskAkvakultur), is the trade association for Danish Aquaculture, representing over 160 Danish companies across the entire value chain. This industry network will be vital for sensor outcome validation and the dissemination of the results to the Danish RAS industry in an efficient and timely manner. 


\section{Communication plan}

FluoRAS integrates partners across the value chain to optimise the projects reach to diverse stakeholders.

1. Danish Sector: The Danish Aquaculture Organisation, Dansk Akvakultur, will be responsible for engaging the Danish aquaculture sector. Through Dansk Akvakultur, aquaculture farmers will validate results in the second half of the project, and their input will be taken into account towards development and co-creation of the final design. Dansk Akvakultur will also be the main channel to reaching Danish manufacturers and operators with the final sensor product's technical performance.

2. EU and Global Sector: partner Kruger A/S, as part of Veolia, have potential to reach EU and global markets with a new Danish product in a sector with strong projected growth.

3. R\&D: DTU will target sector-specific and engineering media outlets (such as Ingeniøren https://ing.dk) to present the major milestone achievements to a broader professional audience, in addition to a broad popular audience through outlets such as Videnskab.dk and ScienceNordic.com.

4. R\&D: Results that meet the quality requirements of research journals will be published by DTU Aqua within peer-reviewed publications, and presented at European Aquaculture Society conferences in 2019-2020, to demonstrate the potential of the FluoRAS sensor for further research and development.

5. FluoRAS will also contribute to GUDPs information activities of relevance to the aquaculture sector in Denmark.

\section{Output}

The final output of the FluoRAS project is an online organic matter sensor and software system that can be fitted to any pre-fabricated commercial or pilot scale RAS. The main components are:

1. a sensor that is customised from relatively inexpensive off-the-shelf fluorescence components;

2. a fluorescence dataset library to interpret the sensor signal; and

3. custom-built control software.

Off-the-shelf fluorescence emission sensors will be selected based on highest performance/cost ratio and will not be a bottleneck for mass system production. These will be customised to allow light sources at the optimal wavelengths determined by WP1, WP2 and WP3.

One of the project partners (Kruger A/S) expertise, is the design and production of custom software-operated water treatment monitoring systems. These currently see such applications including wastewater treatment, as well as drinking water treatment and 
distribution across much of Denmark. Software development and sensor integration is commonplace within the company, and they will therefore deliver the software system required to integrate the FluoRAS sensor into any existing online RAS monitoring network.

The project foreground knowledge and IP will be retained by project partners, but licensed for free to all Danish RAS operators. This approach aims to stimulate open innovation in aquaculture sensor systems within Denmark, which, in combination with off-the-shelf fluorescence sensor hardware, minimises bottlenecks for scalable production. Freely licensed distribution of design specifications to the Danish sector will be in partnership with Dansk Akvakultur - The Danish Aquaculture Organisation. This approach aims to:

1. stimulate open innovation in aquaculture sensor systems within Denmark,

2. lower the barriers to fast Danish application of the sensor, and thus the fast delivery of benefits to Danish RAS operators; and

3. to provide the Danish RAS sector an edge over EU and global competitors and catalyse Danish RAS industry growth.

We believe this to be consistent with the core ethics surrounding the best use of Danish public funding. The additional option for Danish RAS operators is a packaged sensor product, which can be integrated into any existing RAS monitoring network (and likely the most cost effective option for smaller RAS operators). Kruger A/S will be responsible for assembly and distribution of the packaged product, which, given their expanding position in both the Danish and Global aquaculture markets, makes them well suited for distribution of a Danish product to a growing worldwide market (DNB Markets 2017). Royalties shared between the project partners will be outlined in a partner agreement at project onset.

The potential for reverse-engineering the FluoRAS sensor by global operators is not a concern as:

1. the core IP of the system is locked in the signal library which can be protected by standard software engineering techniques, and

2. time is the most valuable component for new technologies (particularly in fast growing industries like RAS) where the first and therefore greatest benefits will be those already involved in the project.

More specifically, this is the entire Danish RAS industry, through Dansk Akvakultur's project dissemination activies.

\section{Market and customers}

Currently, aquaculture provides over $50 \%$ of the worlds seafood production - an inherently increasing number due to an increasing world population, combined with limited or reduced wild fisheries production. In order to reach seafood demand without further overfishing, the industry is looking to RAS as a sustainable, green production method. 
The Danish RAS market is valued at over 97 million $\mathrm{Kr}$ (The Danish AgriFish Agency 2014) - a small but growing proportion of the global RAS industry. The global RAS industry is also growing, and currently estimated at approximately 500 million Kr (DNB Markets 2017) and is therefore a potentially lucrative market for the FluoRAS sensor. Global aquaculture production is predicted to double by 2030 (World Bank 2013) and as the RAS industry expands, so does the potential market and customer base of the FluoRAS sensor system.

The project partner Krüger A/S currently operates a full-scale commercial RAS in Hanstholm, Denmark, where Kingfish are being farmed for high value sashimi production and accounts for $25 \%$ of Danish RAS production alone. In addition to their expertise in developing water quality sensor networks, this makes Kruger A/S an ideal industry partner for developing the FluoRAS sensor system. Kruger A/S also operate a number of other RAS outside of Denmark (including Norway and Switzerland) and are expanding their RAS facilities by 3-4 units annually over the next 5 years. Their unique position within both the Danish and international aquaculture markets makes Kruger A/S an ideal partner in the expansion of the Danish RAS industry, and distribution of Danish RAS products. By making the FluoRAS sensor available to all Danish RAS operators (not only Kruger A/S) with the expertise and industry member-base of Dansk Akvakultur, the Danish aquaculture industry will have a competitive edge in RAS technology, to build and operate the most costeffective, reliable, low-risk and sustainable production facilities possible.

\section{Business case}

RAS industry growth is reliant on improved economics, and environmental sustainability to stay in line with tightening regulations. Within the last 10 years, advances in technology and innovation have been the driver behind industry growth (DNB Markets 2017). Improved economics and environmental sustainability are both addressed by the development of the FluoRAS sensor for online monitoring of organic matter, in that it would enable the reduction of water use, more efficient nitrification processes, more efficient UV treatment for microbial deactivation, and the subsequent economic savings associated with each of these. This could all come at a low cost, compared to the annual savings the sensor could provide.

The market price of current oceanographic fluorescence emission detectors is in the range of 10-30.000 Kr each. Based on the purchase of off-the-shelf products, the modifications required to optimise them to RAS, and the development of software to process the signal, a conservative estimate is a $200 \%$ profit on unit sale price estimate of $150.000 \mathrm{Kr}$ per sensor system. This cost pales in comparison to the total capital cost of a RAS facility. For instance, the capital cost of a Kruger RAS unit is around 65.000.000 Kr (data provided by Kruger A/S) - the FluoRAS sensor system adds only $0,25 \%$ in total capital cost of such a RAS facility. The potential annual cost savings through water and energy for that RAS unit (1.98 mio. Kr) means that a single FluoRAS sensor system could essentially pay for itself within 30 days of optimised RAS operation. As the software development cost is a large proportion of the total (and a single fixed cost) the cost of each subsequent FluoRAS 
sensor system will then decrease, as more units are produced. The low proportional cost of the system compared to annual estimated energy and water savings, also makes the FluoRAS sensor system a competitive product to the aquaculture market as stand-alone product.

Due to the low purchase cost of the sensor system, and since all RAS require nitrification treatment, the sensor purchase and integration would be highly economical to even the smallest of RAS operators, both in Denmark and abroad. As the sensor can be integrated into any operating RAS unit, there is a well-defined, large, and expanding market for the FluoRAS sensor product. This also means that every RAS facility is part of the potential market base for the FluoRAS sensor system. By 2020, this will include between 30 and 300 new commercial RAS systems - which equates to between 3-30 mio. kr. of potential sensor revenue by 2020 figures (DNB Markets 2017).

Project partner Krüger A/S currently operates one large commercial RAS facility in Hanstholm, Denmark, as well as in Fredrikstad, Norway (operational start of 2018), and Lostallo, Switzerland, with plans for moderate expansion of 3-4 operational units per year over the next 3-5 years. Dansk Akvakultur (The Danish Aquaculture Farmers Association) also has a membership base of over 160 Danish aquaculture producers. By integrating them as a project partner, the Danish RAS industry will be accessed through their unique aquaculture professional member network, and thus provide the optimal dissemination of the FluoRAS sensor.

\section{Buisness model}

The business model integrates economic benefits for each sector in the short RAS value chain: RAS Designers $\rightarrow$ RAS facilities builders $\rightarrow$ RAS operators $\rightarrow$ seafood sales. The model is positioned in a sector with predicted large national and global growth. Danish aquaculture production has been targeted for 25\% growth by 2020 (Ministry of Environment 2014) and global aquaculture production is predicted to double by 2030 (World Bank 2013).

For an initial, and one off investment of less than 4.5 million DKK by GUDP, the project offers significant return on investment with a product that could save approximately 8 million DKK per year in Danish RAS operating costs, and up to 30 million DKK in sensor revenue by 2020 estimates.

As well as over 8 times initial Return On Investment (ROI) for GUDP by 2020, this can measurably add to the competitiveness of Danish-built facilities, lower running costs for Danish aquaculture farmers and reduce the risk of loss of stock due to outbreaks (up to 20 million DKK per event). Ultimately, running costs savings and seafood health safety benefits would be passed on to the consumer. The FluoRAS sensor system can be also be marketed as a Danish product to supply Danish and global RAS operators. Relative design simplicity based on modified off-the-shelf hardware and purpose-built software package, also allows for scaling up production to match expected sector growth. The dissemination 
and promotion activities with Dansk Akvakultur will provide the best pathway for dissemination and access to the Danish RAS industry (independent from RAS design or manufacturer), and in partnership with Kruger A/S, and their global industry links through their Veolia parent company, will enable wider access to the global RAS market.

All calculations for the figures above have been performed based on conservative estimates, allowing for further growth in the business model.

\section{Calculations}

As described in the text, calculations in Table 1and Table 2 are extrapolated from potential savings per Kruger RAS unit (data supplied by Kruger A/S) which accounts for approximately $25 \%$ of the current Danish RAS production market. As such, the calculations for a Kruger RAS unit are multiplied by 4, to scale up to the estimated potential savings over the size of the current Danish RAS industry.

The project's specific GREEN effects:

1. $30 \%$ more nitrification efficiency (Eding et al. 2006): The calculations are based on operational data provided by Kruger A/S, where $150 \mathrm{~kg} \mathrm{~N}$ as ammonia are used per day from a commercial scale RAS. $150 \mathrm{~kg} \times 365$ days $=58,8$ t $\mathrm{N}$ per annum, and thus a $30 \%$ saving of this amount equates to $16,4 \mathrm{t} \mathrm{N}$ saved per year per Kruger RAS unit, and multiplied by 4 to represent the total Danish RAS industry savings (65,6 tonnes of Nitrogen per year).

2. $30 \%$ more UV efficiency (He et al. 2012): The calculations are based on operational data provided by Kruger A/S, where the UV treatment unit power consumption is $64.824 \mathrm{kWh}$ per year. These numbers are then multiplied by the average 2015 Danish $\mathrm{CO}_{2}$ output of $0,202 \mathrm{~kg} / \mathrm{KWh}$ (energinet.dk), equating to $13,1 \mathrm{t}$. of $\mathrm{CO}_{2}$ per year. A $30 \%$ saving of this, is 3,9 t. $\mathrm{CO}_{2}$ per year for a single Kruger RAS unit, which can produce up to $1200 \mathrm{t}$ of fish product per year. This is then multiplied by 4 to represent the total Danish RAS industry savings (15,6 tonnes of $\mathrm{CO}_{2}$ per year).

3. Water efficiency: The calculations are based on Kruger data, where as little as 100 $\mathrm{L}$ of water can be used per kg of feed per day. Multiplied by the amount of feed per day at full operational capacity (4.0 t), equates to $0.4 \mathrm{ML}$ per day, or $146 \mathrm{ML}$ per year. $30 \%$ of this is $43,8 \mathrm{ML}\left(43.800 \mathrm{~m}^{3}\right)$ per year saving, per Kruger RAS unit. This is then multiplied by 4 to represent the total Danish RAS industry savings (175.200 $\mathrm{m}^{3}$ of $\mathrm{H}_{2} \mathrm{O}$ per year).

The project's specific ECONOMIC effects:

1. UV efficiency: The $30 \%$ UV treatment energy economic savings are based on energy saving calculations in Table 1 . This equates to $64.824 \mathrm{kWh}$ (Kruger data) $\mathrm{x}$ $30 \%=19.447 \mathrm{kWh}$ energy saving per year, multiplied by the conservative industry cost of electricity $0.67 \mathrm{DKK} / \mathrm{kWh}=13.030 \mathrm{Kr}$ savings in UV treatment energy per 
year, per Kruger RAS unit. This is then multiplied by 4 to represent the total Danish RAS industry savings (52.120 DKK per year).

2. Water efficiency: The $30 \%$ water economic savings are based on water consumption savings in Table 1. This equates to $43,8 \mathrm{ML}$ water saving per year, and at a conservative water cost of 45 DKK per 1000 litres, this equates to 1.97 million DKK in annual water savings, per Kruger RAS unit. This is then multiplied by 4 to represent the total Danish RAS industry savings (7.9 million DKK per year).

3. FluoRAS sensor revenue: Global RAS expansion by 2020 is expected to be over 150.000 tonnes per year (DNB Markets 2017). Typical RAS production sizes are between 500 and $1.5 \mathrm{t}$ per year, however this is expected to increase up to $5.000 \mathrm{t}$ per RAS annually (DNB Markets 2017). Allowing for this range in system capacity (500-5.000 t per RAS annually) this would equate to anywhere between 30-300 new RAS facilities which could benefit from the FluoRAS sensor by 2020 . At 100.000 DKK per FluoRAS sensor system, this equates to between 3 million and 30 million DKK in FluoRAS sensor revenue.

\section{Funding program}

The Ministry of Environment and Food, GUDP (Green Development and Demonstration Programme) - Rejected

\section{Hosting institution}

Technical University of Denmark - DTU Aqua

\section{References}

- $\quad$ Anonymous (2017) Mystisk massedød på dansk laksefarm. http://nyheder.tv2.dk/ business/2017-07-06-mystisk-massedod-pa-dansk-laksefarm. Accessed on: 2017-7-06.

- $\quad$ DNB Markets (2017) Seafood Special Report - A deep dive into land-based farming. DNB Markets, Oslo.

- $\quad$ Eding EH, Kamstra A, Verreth JA, Huisman EA, Klapwijk A (2006) Design and operation of nitrifying trickling filters in recirculating aquaculture: $A$ review. Aquaculture Engineering 34: 234-260. https://doi.org/10.1016/j.aquaeng.2005.09.007

- Hambly A, Arvin E, Pedersen L-F, Seredynska-Sobecka B, Stedmon C (2015) Characterising organic matter in recirculating aquaculture system with fluorescence EEM spectroscopy. Water Researcn 83: 112-120. https://doi.org/10.1016/ j.watres.2015.06.037

- He X, Pelaez M, Westrick JA, O’Shea KE, Hiskia A, Triantis T, Kaloudis T, Stefan MI, de la Cruz AA, Dionysiou DD (2012) Efficient removal of microcystin-LR by UV-C/ $\mathrm{H}_{2} \mathrm{O}_{2}$ in synthetic and natural water samples. Water Research 46: 1501-1510. https:// doi.org/10.1016/j.watres.2011.11.009 
- Hudson N, Baker A, Reynolds DM (2007) Fluorescence analysis of dissolved organic matter in natural, waste and polluted waters: A review. Rivers Research and Applications 23 (6): 631-649. https://doi.org/10.1002/rra.1005

- Ministry of Environment (2014) Strategi for bæredygtig udvikling at akvakultursektoren I Danmark 2014-2020. [Strategy for sustainable development in the aquaculture sector in Denmark 2014-2020]. Miljøministeriet [In Danish].

- Moestrup $\varnothing$, Hansen G, Daugbjerg N, Lundholm N, Overton J, Vestergård M, Steenfeldt SJ, Calado AJ, Hansen PJ (2014) The dinoflagellates Pfiesteria shumwayae and Luciella masanensis cause fish kills in recirculation fish farms in Denmark. Harmful Algae 32: 33-39. https://doi.org/10.1016/i.hal.2013.12.002

- OECD (2016) The Ocean Economy in 2030. OECD Publishing, Paris. [ISBN 978-92-64-25172-4]

- The Danish AgriFish Agency (2014) Annual Report on fishing fleet capacity 2014 Denmark. http://lbst.dk/fileadmin/user_upload/NaturErhverv/Filer/Fiskeri/Kort_statistik/ Statistik/flaaderapport/DK Fleetreport 2014.pdf. Accessed on: 2015-6-26.

- World Bank (2013) Fish to 2030: Prospects for Fisheries and Aquaculture. Agriculture and environmental services discussion paper. no 3.. World Bank Group, Washington D.C.. URL: http://documents.worldbank.org/curated/en/458631468152376668/Fishto-2030-prospects-for-fisheries-and-aquaculture 